\title{
The Not So Obvious Impact of COVID 19: The Hidden "Curriculum"
}

\section{Fatimah Lateef}

Dept. of Emergency Medicine, Singapore General Hospital

Corresponding Author: Fatimah Lateef, Dept. of Emergency Medicine, Singapore General Hospital.

Received Date: December 25, 2021; Accepted Date: January 06, 2022; Published Date: January 13, 2022

Citation: Fatimah Lateef. (2022) The Not So Obvious Impact of COVID 19: The Hidden “Curriculum”. J. Immunology and Inflammation Diseases Therapy. 5(1); Doi:10.31579/2637-8876/025

Copyright: () 2022 Fatimah Lateef. This is an open-access article distributed under the terms of The Creative Commons Attribution License, which permits unrestricted use, distribution, and reproduction in any medium, provided the original author and source are credited.

\begin{abstract}
:
The last two years of the Covid 19 pandemic has certainly brought on and inculcated a variety of changes, new practices, innovative approaches and altered mindsets. Some of these were intended, planned and incorporated into pathways and practices. There were many lessons and new experiences. Without our complete realization, there were also many less obvious lessons: the hidden curriculum. This refers to the unwritten, unspoken, unplanned and less obvious values, behaviour and norms practised or experienced during the pandemic. The hidden curriculum is conveyed and communicated without our direct awareness and intent.

The hidden curriculum will certainly contribute towards healthcare staff resilience, handling of stressors, decisions on utilization of resources and patient care. Not to be forgotten, it will also impact how they develop friendships, partnerships, collaborations, negotiate their self-development and strengthen their sense of purpose and challenge assumptions.

In this paper, the author, who worked at the frontline during the pandemic shares some of her views on the new healthcare landscape, mindset changes, technology adoption, psychological safety and the meaning of 'staying home'. They represent her views, coloured by her experiences as an emergency physician, a medical educator, academic medicine practitioner and researcher.
\end{abstract}

Keywords : hidden curriculum; Covid 19; technology; teleconsultation; psychological safety

\section{Introduction}

Covid 19 brought on new trends and practices which continue to evolve. It presented a real-life learning crisis. In the early stages of the pandemic, there was a decrease in the number of patients seeking medical care, decrease in the number of referrals for urgent specialists care, delay in follow up as well as in commencing treatment for conditions such as cancer. As medical practitioners and scientists uncovered more information on the characteristics of the virus, more targeted management and clinical pathways began to be conceived. With this greater amount of knowledge made public, patients started to return for care in institutions and numbers started to rise. In the second and subsequent waves of the Covid 19 pandemic, the trend of more serious clinical manifestations began to show and this added more pressure on hospital capacity, general ward beds, isolation beds as well as intensive care unit beds. By now, nations of the world are facing their fourth or fifth waves of case peaks related to the pandemic. [1-3]

The numbers of patients with Covid 19 too had its ups and downs. With each new variant, arising from genetic shift and drift, numbers peaked and both community and institution guidelines were reviewed and customized accordingly once more. There was much adaptation needed with the changing profile and landscape. The last two years with the pandemic has certainly brought on and inculcated a variety of changes, new practices, innovative approaches and altered mindsets. Some of these were intended, planned and incorporated into pathways and practices. [1, 4-6] There were also many lessons and new experiences. Without our complete realization, there were also many less obvious lessons: the hidden curriculum. This refers to the unwritten, unspoken, unplanned and less obvious values, behaviour and norms practised or experienced during the pandemic. The hidden curriculum is conveyed and communicated without our direct awareness and intent. Elements of the hidden curriculum can of course be positive or negative in terms of impact. Alternatively, people, society, and culture can certainly impact the hidden curriculum. [7-10] The following discussion covers some of the lessons we learnt from the pandemic and the hidden curriculum, embedded within them.

\section{Change Management and Adaptation}


Everyone went through changes in so many ways, during the pandemic. Our lifestyles changed, just as the way we work. Without being very obvious the pandemic has inculcated many change agents. At the frontline of healthcare institutions, we negotiated pathways for patient management, segregating acute respiratory illnesses (ARI) from non ARI, BAU (business as usual) patients, the route COVID positive patients will take as they are being transported to isolation wards and intensive care units as well as the management of acutely ill Covid 19 positive patients. We conform to institution guidelines strictly for our own and our patients' safety. This has made us more versatile and adaptable to the rapid changes in our approach to patient care during pandemics. It inadvertently made us safer practitioners and proponents of safe practices. Today, 2 years down the line, many of these practices have become second nature to us. We diligently execute and apply them strictly in the appropriate contexts. [4-6] The hidden curriculum in our subconscious mind has certainly help us manage change better. The changes in workflow, clinical pathways, testing regimes, vaccination protocols, PPE (personal protective equipment) recommendations, as the pandemic progressed have enabled us to have a more growth mindset. It has made us more versatile in preparing for future crises and pandemics in the new norm and beyond. It provided us commitment reinforcements. Finally, the Covid 19 platform allowed medical practitioners to realize how realistic 'unlearning and relearning' is. This demonstrates how dynamic healthcare education can be. $[9,10]$

\section{Teleconsultation, Training and Patient Care}

When face to face consultations were challenged in the early phases of the pandemic, we sought remote and virtual interactions to provide treatment and advice for our patients. Whilst many may have been antagonistic to this initially, options were not many. In order to carry on with providing care for our patients, many embarked on this and now are familiar and comfortable with it. In fact, it has become so convenient, saving on travel time, cutting non-essential face to face interaction with healthcare personnel and has enabled anytime, cross-country and even cross-border consultations. It has certainly facilitated the work of visiting physicians and consultants. For many it has become a learnt and adopted practice. In the arena of medical education, virtual connectivity provided the way forward in order not to be too disruptive of training, curriculum development and progress. Some examinations were conducted virtually, interviews were carried out remotely, e-learning became widespread and many more innovative initiatives came about. [11-15]

\section{Teamwork and Systems-based Practice}

In healthcare, the inter-dependence of specialties is crucial. No specialty stands alone and the practice of medicine is not a solo endeavour. Team practice, inter-professional collaborative practice and good systems-based practice have all been strengthened during the pandemic. Enhanced, more robust and respectful relations between disciplines is likely to be at its best. Residents in training get to experience and understand this better as they are involved and embedded in its practice and execution. This hidden curriculum will certainly help shape their values, culture and ethics of practice. $[9,10,13,15,16]$

\section{Psychological safety and wellness}

The pandemic has also highlighted our vulnerabilities together. We began to look out for each other even more. The importance of personal wellness and psychological safety for healthcare staff has never been more prominent than now, in its current state. Wellness hotlines, peer support programmes, online advice and overt show of care and concern have sprouted. There is greater appreciation for self and colleagues. The public and patients too are more empathetic towards healthcare staff. We should not underestimate the power and impact these have had on our perseverance and spirit. Kindness and respect can certainly go a long way. This is indeed embedded in the hidden curriculum. [17, 18]

\section{Technology Galore!}

The pandemic provided a platform for technology development in Medicine to flourish at an even faster rate. It is now being utilized in almost all aspects of care., from registration and administration, to recording and documentation, surgical procedures, medication dispensing, investigations and even home-based surveillance for patients, amongst others. During the pandemic, technology was used frequently in caring for patients in isolation rooms. For example in taking their vital signs, nurses need not go into the rooms all the time. The vital signs can be configured to be taken from smart devices and transmitted to monitors at a station outside the room. Other forms of communications with patients in these rooms can be conducted via the use of an i-pad. [19]

There will more developments anticipated in a wider variety of practice areas, in the coming years. Covid 19 has provided the necessary impetus for sowing the seeds in innovation and technological developments, and it will have many spin-offs and follow through in the coming years. There are also now more grants related to innovations in Medicine. This is aligned with the objective to enhance and improve work processes and the way things are carried out. There is also greater use of technology driven education for training and preparation for complex surgery, procedures and preparedness protocols and pathways. Healthcare professionals of the future will be more technology-savvy. Processes will become faster and more efficient. This is already being incorporated gradually into practice as part of the formal curriculum, as well as the less overt, hidden curriculum. $[1,5,19]$

\section{Home is Where the Heart is}

"Work from home", "home-based learning" and the such have become our tag line during the pandemic. People have now become so used to remote connectivity, from the comforts of their home. It was awkward in the beginning and people missed the face to face contact. However, by now, we may even crave for this as we have realized the advantages these offer. These remote connections have now been incorporated into our hidden curriculum. We are now versatile in conducting remote meetings and lectures, across borders and continents, 24 hours a day. The spin-offs for this would include more virtual communities of practice, international policy groups or professional communities. All these collaboration, networking and interactions are done without having to travel out of our homes. Though some may argue these are not optimal interactions, we cannot deny the fact that the last two years of doing so has enabled us to form all these. In fact, many of these continue to be nurtured and strengthened. The pandemic also has enabled many of us to spend more time at home with our families. Previously, it was not uncommon for healthcare staff to find it a challenge to have meals together and meet up with their families during work days. With more staying home, outside their shifts and work hours, we cannot deny the fact that we now have more time with our families. However, this also may bring back memories of the early days of the pandemic where many frontline healthcare staff were concerned about returning home to their families, worried that they may cause transmission to take place. At that time, there were staff who decided to stay apart. When lock-downs and restrictions were imposed, loneliness and isolation was a major concern as well. Not forgetting seniors who could not meet their families or go out to get their care and consultations. We are in a better position today and perhaps these initial challenging experiences may have helped us realize the importance of families, friends, communities and social bonds.

\section{Productivity in Publications}


The number of Covid 19 related publications sky-rocketed the last 2 years. Healthcare professionals, academicians, scientists and others generated a tremendous amount of new ideas, research and best practices sharing across multiple journals and scientific publications. The hidden curriculum is that many more people are writing for publication and this included both experienced authors as well as first time authors. [20] The latter provided a good platform for residents to inculcate their knack for writing and publishing. It also provided opportunities for academic work and scholarly activities as well as the conduct of literature scanning and searches. The hidden curriculum part of this may arise from them learning to form collaborations, multi-centre partnerships and global net-working. Indeed, this can set the platform for more global sharing of data across institutions, communities and nations.

\section{Conclusion}

As we continue to negotiate the pandemic today, many healthcare staff will recollect experiences and obvious lessons. The impact of the less obvious hidden curriculum must not be under-estimated. This can have significant bearing on our future moves, decisions, development, growth, patient care, relationships, how we learn and our growth mindset. These lessons are beyond the four walls of the classroom. They are experiential and powerful. The sub-liminal and sub-conscious learning is useful, as we realize our unity of purpose.

\section{References}

1. Farrow RJ, Labrador AC, Crews JD. Healthcare design. Road to flexibility: strategic interventions. Available at : https://healthcaredesignmagazine.com/trends/architecture/road -flexibility-strategic-interaction/ (last accessed on 2 Jan 2022)

2. Lateef F. The Impact of the Covid 19 pandemic on Emergency Department attendances: What seems to be keeping the patients away? Journal of Emergencies, Trauma and Shock 2020; 13 : 246-251

3. Wadhera RK, Wadhera P, Gaba P. Variations in Covid 19 hospitalizations and deaths across New York City boroughs. JAMA 2020; 323(21): 2192-2195

4. Ashcroft J, Davies RJ, Brennan FA. Facilitating resilience in the return to surgical practice. Correspondence. Letter to Editor. The Surgeon 2021; 19: 380-383

5. Archuleta S, Cross G, Somani J, Lum L, Santosa A, Alagha RA et al. Responding to Covid 19: How an academic infectious diseases division mobilized in Singapore. BMC Med 2020; 18(1): 179

6. Lin RJ, Lee H, Lye DCB. From SARS to Covid 19: The Singapore journey. The Med J of Australia 2020; 212(11): 497$502 \mathrm{el}$
7. Macleod A. The hidden curriculum: is it time to reconsider the concept? Med Teach 2014; 36: 539-540

8. Lawrence C, Mhlaba T, Stewart KA. The hidden curriculum of medical education: a scoping review. Acad Med 2018; 93: 648656

9. Botros M, Cooper AZ, The hidden curriculum of the Covid 19 pandemic: Perspectives. J Grad Med Edu 2020; 550-552. Doi:http://dx.doi.org/10.4300/JGME-D-20-00502.1

10. Alsabaie MA. Hidden curriculum as one of the current issues of curriculum. J Edu and Pract 2015; 6(33): 125-128

11. Kludacz-Alessandri M, Hawrysz L, Kovneta P, Gierszewska G, Pomaranik W, Walczak R. The impact of teleconsultation on general practitioners during Covid 19: Case study from Poland. PLOS ONE 2020; 16(7): e0254960

12. Lateef F. Computer based simulation and online teaching netiquette in the time of Covid 19. EC Emergency Medicine and Crit Care 2020; 4.8

13. Lempp H. Seale C. The hidden curriculum in the undergraduate medical education: A qualitative study of medical students perception of teaching. BMJ 2004; 329: 770-773

14. Fischer D, Mak K. Exiting the pandemic in Singapore. Commentary. BMC Med 2021; 19: 238

15. Lateef F. Covid 19 pademic: a disruption or a fertile experiential learning platform for EM residents. Edu in Med J, 2020; 12(3): 39-47

16. Patel SY, Mehrotra A, Huskamp HA, Uscher-Pines L, Ganguli I, Barnett ML. Trends in outpatient care delivery and telemedicine during the Covid 19 pandemic in the US. JAMA Intern Med 2021; 181(3): 388-391

17. Lateef F. Culture of psychological safety in the Emergency Department: Do not forget the hidden curriculum. Archives of Emergency Med and Intensive care 2021; 4(1): 18-26

18. Lateef F. Through the ethical lenses: There is more than meets the eye with Covid 19. Archives of Emergency Medicine and Intensive Care 2020; 391): 6-16

19. Healthcare technology development is being accelerated by the Covid 19 pandemic. Healthcare Finance. Available at : https://healthcarefinancenews.com/news/healthcaretechnology-development-being-accelerated-covid-19pandemic (last accessed on 2 Jan 2022)

20. Covid 19 research updates: How many pandemic papers have been published. August 2020. Available at: https://Natureindex.com/news-blog/how-coronavirus-isdriving-research-practices-and-publishing (last accessed on 2 Jan 2022) 
(c) (†)

This work is licensed under Creative

Commons Attribution 4.0 License

To Submit Your Article Click Here: $\quad$ Submit Manuscript

DOI: $10.31579 / 2637-8876 / 028$
Ready to submit your research? Choose Auctores and benefit from:

$>$ fast, convenient online submission

$>$ rigorous peer review by experienced research in your field

$>$ rapid publication on acceptance

$>$ authors retain copyrights

$>$ unique DOI for all articles

$>$ immediate, unrestricted online access

At Auctores, research is always in progress.

Learn more https://auctoresonline.org/journals/immunology-andinflammation-diseases-therapy- 